\title{
Oxytocin synthesis within the normal and neoplastic breast: First evidence of a local peptide source
}

\author{
PAOLA CASSONI, TIZIANA MARROCCO, ANNA SAPINO, ELENA ALLIA and GIANNI BUSSOLATI
}

Department of Biomedical Sciences and Human Oncology, University of Torino, Torino, Italy

Received September 5, 2005; Accepted October 21, 2005

\begin{abstract}
The role of the neurohypophyseal peptide oxytocin (OT) and its receptor (OTR) in the breast has been described mainly in relation to breast feeding or to neoplastic growth regulation. We demonstrate here the presence of OT synthesis within the breast under both physiological and neoplastic conditions. In order to clarify whether normal epithelial and myoepithelial cells could synthesize OT, the two different cell types were separated using immunomagnetic technique after enzymatic digestion of breast specimens obtained during reductive mastoplasty. The freshly isolated cells as well as primary stabilized cultures derived from purified normal breast epithelial and myopithelial cells were then studied. Both epithelial and myoepithelial cells contained the mRNA for OT and OTR; however, only myoepithelial cells showed an effective OT synthesis and detectable peptide release in the culture medium. Moreover, OT expression was studied at mRNA and protein level in 10 human breast carcinoma cell lines. OT mRNA was present in half (5 out of 10) of the breast carcinoma cell lines tested, and OT was synthesized and released in the cell medium, irrespective of the estrogen receptor status of the different cell lines. However, in the two $\mathrm{ER}^{+}$cell lines actively producing OT, such synthesis was significantly increased following estradiol $\left(\mathrm{E}_{2}\right)$ treatment. These data altogether suggest the existence of a local OT source within the normal as well as within the neoplastic breast, and that such synthesis can be modulated by $\mathrm{E}_{2}$.
\end{abstract}

\section{Introduction}

The hypothalamic nonapeptide oxytocin (OT) is known to play a role in many biological functions including lactation, parturition, sexual and maternal behavior (1), control of food intake (2), and regulation of cells growth under both physiological and neoplastic conditions $(3,4)$. These actions are all mediated through the activation of specific G-coupled transmembrane receptors (OTR) (5).

Correspondence to: Professor Gianni Bussolati, Department of Biomedical Sciences and Human Oncology, University of Torino, via Santena 7, I-10126 Torino, Italy

E-mail: gianni.bussolati@unito.it

Key words: oxytocin, oxytocin receptors, breast cancer, estrogen receptors, estradiol
In the breast, OTR were detected in contractile myoepithelial cells, in primary breast carcinomas and in breast carcinoma cell lines (6-8). In breast carcinoma cells, OT regulates cell proliferation via OTR, determining inhibition of cell growth in vitro and in vivo (8-11). In a previous study on breast carcinoma cell lines we demonstrated also that OT modulates the expression of estrogen receptor $\alpha(\mathrm{ER} \alpha)$ in MCF7 cells, both at mRNA and protein level (12). Moreover, estradiol $\left(\mathrm{E}_{2}\right)$ regulates OTR binding and expression in MCF7 ER-positive breast cancer cell line (13). All these findings taken together demonstrate the existence of a functional ER/OTR interplay in breast cancer which can be possibly involved in different biological effects of both ligands, $\mathrm{E}_{2}$ and OT. However, although the presence of OTR in breast cancer cells and primary carcinomas has been extensively investigated, no data are available to date on the eventuality of a local synthesis of OT in normal breast epithelial and myoepithelial cells and/or in neoplastic breast cells.

Actually, the OT synthesis by neoplastic cells in general has been scarcely investigated. Pequeux et al described OT synthesis, as well as OTR expression, in cell lines from human small cell carcinoma of the lung (14). In this model, the authors demonstrated the existence of a functional OT-mediated autocrine-paracrine signaling actively implicated in growth and development of this type of tumor (14). On the contrary, in another OTR-positive carcinoma displaying a potential endocrine differentiation, such as prostatic carcinoma, the mRNA for OT was absent in neoplastic cells (15).

The aim of the present work was to investigate oxytocin production by normal breast-derived cells, either of myoepithelial or epithelial origin, as well as in breast carcinoma cell lines. According to the previous reported data on the estrogen-OT interplay, we also aimed to verify the possible effect of $E_{2}$ on the OT secretion and on OTR regulation in these different cell subtypes. The presence of OT-mRNA was verified by reverse transcriptase polymerase chain reaction (RT-PCR). The effective synthesis and release of OT, in absence or presence of $\mathrm{E}_{2}$, was assessed by an enzyme immunoassay in cell supernatants. Finally, the effect of $E_{2}$ on OTR modulation was investigated by flow cytometry analysis.

\section{Materials and methods}

Cell lines and cell culture. Human breast cancer cell lines (MCF7, T47D, Hs578T, SKBR3, MDA-MB4353, BT474, BT549, BT20, ZR75 and MDA-MB-231) were all purchased 
Table I. Sequences of OT and OTR PCR primers and Southern probes.

\begin{tabular}{|c|c|c|c|}
\hline Primer & Sequence & Position & GenBank accession \\
\hline \multicolumn{4}{|c|}{ ß2-microglobulin } \\
\hline Forward & 5'-ACC CCC ACT GAA AAA GAT GA-3' & 284-303 & XM_007650 \\
\hline Reverse & 5'-ATC TTC AAA CCT CCA TGA TG-3' & $378-397$ & XM_007650 \\
\hline \multicolumn{4}{|l|}{ OTR } \\
\hline Forward & 5'-CCT TCA TCG TGT GCT GGA CG-3' & $1469-1488$ & NM_000916 \\
\hline Reverse & 5'-CTA GGA GCA GAG CAC TTA TG-3' & $1840-1859$ & NM_000916 \\
\hline \multirow[t]{2}{*}{ Probe } & 5'-GGA GCA GCA CAG GAA GCG GTC CAC & $1618-1665$ & NM_000916 \\
\hline & GAG TTC GTG GAA GAG GTG GCC CGT-3' & & \\
\hline \multicolumn{4}{|l|}{ OT } \\
\hline Forward & 5'-ACC ATT TCT GGG GTG GCT AT-3' & $41-50$ & AW270827 \\
\hline Reverse & 5'-GGT CTT GGG CCT CTG CTG-3' & $172-189$ & AW270827 \\
\hline Probe & 5'-GTG TTC GGA GCC ATC AAG TT-3' & 89-108 & AW270827 \\
\hline
\end{tabular}

from the ATCC (Rockville, MD). All cells were grown in a $5 \% \mathrm{CO}_{2}$ humidified atmosphere in RPMI, DMEM or ISCOVE medium (Gibco, Paisley, Scotland) with 10\% FCS (Gibco), penicillin/streptomycin and fungizone (Gibco).

Tissue collection and cell purification. Human mammary tissues were obtained as discard material from six reduction mammoplasties, following informed consent of the patient. The glandular cells were separated from the stromal cells with a procedure involving dissection, enzymatic digestion and immunomagnetic cell separation. Tissues were processed in a digestion mixture with collagenase type IA $200 \mathrm{U} / \mathrm{ml}$ (SigmaAldrich, St. Louis, MO) and hyaluronidase 100 U/ml (SigmaAldrich) as previously described $(16,17)$. The enzymatic reaction was stopped when stroma was broken down and basement membrane was digested. Mammary epithelial and myoepithelial cell purification was performed by Dynabeads Magnetic Separation (Dynal Biothec, Oslo, Norway). Myoepithelial cells were selected using $\alpha \mathrm{CD} 10$ primary antibody (Novocastra, 1:50, clone 56 c6, Bentonlane, Newcastle, UK) incubated for $1 \mathrm{~h}$ at $4^{\circ} \mathrm{C}$ and using Dynabeads M-450 goat anti-mouse $\operatorname{IgG}\left(1-2 \times 10^{7}\right.$ beads $\left./ \mathrm{ml} \mathrm{sample}\right)$ for $45 \mathrm{~min}$ at $4^{\circ} \mathrm{C}$, providing gentle mixing. The resulting complex was removed from the suspension by means of a magnet. Epithelial cells were then selected using EMA monoclonal antibody 1:50 (clone E29, Dako, Glostrup, Denmark) following the previously detailed procedure. Using ICC procedures with the specific antibodies, the phenotype of the separated cells was verified and reconfirmed in cells seeded on a glass coverslip. Purified mammary cells were then grown in culture flask in DMEM/Ham's F12 1:1 medium (Sigma) supplemented with $10 \% \mathrm{FCS}, 0.01 \mathrm{mg} / \mathrm{ml}$ insulin, $500 \mathrm{ng} / \mathrm{ml}$ hydrocortisone, $20 \mathrm{ng} / \mathrm{ml} \mathrm{EGF}, 100 \mathrm{ng} / \mathrm{ml}$ cholera toxin. In addition, to verify the results obtained in the freshly separated cells, we used two established cultures of human myoepithelial and epithelial cells respectively, a kind gift of Professor S.R. Lakhani's group (Department of Histopathology, Royal Free and
University College Medical School, University College, London, UK) (18).

Detection of OTR and OT MRNA by RT-PCR in breast cancer cell lines, and purified cell components from normal breast tissue. Total RNA was extracted from the cell lines and the different cell types obtained by breast tissue digestion and dynabeads separation using the TriRiagent extraction kit (Molecular Research Center Inc., Cincinnati, OH, USA) following manufacturer's recommendations. The concentration of RNA was estimated by spectrophotometry, and RNA degradation was assessed by $1 \%$ agarose gel electrophoresis. Total RNA $(1 \mu \mathrm{g})$ was digested to avoid DNA contamination with $10 \mathrm{U}$ of RNase-free DNase (Boehringer-Mannheim, Mannheim, Germany) in a $10 \mu 1$ solution containing $2 \mathrm{mM}$ $\mathrm{MgCl}_{2}$ at RT for $10 \mathrm{~min}$, then heated for $5 \mathrm{~min}$ at $70^{\circ} \mathrm{C}$ to inactivate DNase. Oligodeoxythymidine primer (40 pM) (oligo $\mathrm{dT}_{16}$ ) was then added and the solution was heated at $70^{\circ} \mathrm{C}$ for $10 \mathrm{~min}$, then chilled on ice to allow primer hybridization. The final solution was reverse-transcribed with $100 \mathrm{U}$ of Superscript Reverse Transcriptase (Gibco-BRL, Gaithersburg, USA), and complementary DNA (cDNA) was generated in a $50 \mu 1$ final reaction volume containing $50 \mathrm{mM}$ Tris- $\mathrm{HCl} \mathrm{pH} 8.3$, $75 \mathrm{mM} \mathrm{KCl}, 3 \mathrm{mM} \mathrm{MgCl} 2,10 \mathrm{mM}$ DTT, $1 \mathrm{mM}$ dNTPs and $20 \mathrm{U}$ of RNasin (Promega, Madison, WI, USA). The solution was heated at $37^{\circ} \mathrm{C}$ for $90 \mathrm{~min}$, then the enzymes inactivated by heating at $70^{\circ} \mathrm{C}$ for $10 \mathrm{~min}$. Negative control samples for further PCR amplification included omission of the reverse transcriptase enzyme.

RNA quality was assessed by amplification of B2-microglobulin mRNA. OTR primers were designed according to Takemura et al (19). Primer sequences and location for OTR, OT and B2-microglobulin PCR primers are listed in Table I. PCR experiments were carried out in a final volume of $10 \mu \mathrm{l}$ containing $1 \mu \mathrm{l}$ of $\mathrm{cDNA}, 1 \mu \mathrm{M}$ of sense and antisense primer, $200 \mu \mathrm{M}$ dNTP, 1X PCR buffer (10 mM Tris-HCl pH 8.3, $50 \mathrm{mM} \mathrm{KCl}$ ) (AmpliTaq, Perkin-Elmer, Roche, NJ), $1.5 \mathrm{mM}$ 
Table II. OT and OTR mRNA detection in human breast cancer cell lines.

\begin{tabular}{|c|c|c|c|}
\hline \multicolumn{2}{|l|}{ Cell line } & \multirow{2}{*}{$\begin{array}{c}\text { OT mRNA } \\
-\end{array}$} & \multirow{2}{*}{$\begin{array}{c}\text { OTR mRNA } \\
+\end{array}$} \\
\hline MCF7 & & & \\
\hline T47D & $\mathrm{ER}^{+}$ & + & + \\
\hline BT474 & & + & + \\
\hline ZR75 & & - & + \\
\hline Hs578t & & - & + \\
\hline SKBR3 & & + & + \\
\hline MDA-MB4353 & $\mathrm{ER}^{-}$ & - & + \\
\hline BT549 & & + & + \\
\hline BT20 & & + & + \\
\hline MDA-MB-231 & & - & + \\
\hline
\end{tabular}

$\mathrm{MgCl}_{2}$ and $0.5 \mathrm{U}$ of Taq polymerase (AmpliTaq Gold, PerkinElmer). Each reaction consisted of 35 cycles of denaturation at $94^{\circ} \mathrm{C}$ for $45 \mathrm{sec}$, annealing at $55^{\circ} \mathrm{C}$ (ß2-microglobulin and OTR) and $61^{\circ} \mathrm{C}(\mathrm{OT})$ for $1 \mathrm{~min}$, and extension at $72^{\circ} \mathrm{C}$ for $1 \mathrm{~min}$. PCR products were then visualized under UV light in $1 \%$ agarose gels containing ethidium bromide. MCF7 human breast carcinoma cells and normal human hypothalamus (obtained from autopsy) were used as positive controls for OTR and OT, respectively. Negative control samples included omission of cDNA in the PCR mixture.

To further test RT-PCR product specificity, Southern blot analysis (SBA) was performed. Probe sequences are reported in Table I. Membranes were hybridized at $42^{\circ} \mathrm{C}$ overnight with 25 pmols of digoxigenin-labelled OTR oligonucleotide probe. The membranes were then washed with $2 \mathrm{X}$ SSC$0.1 \%$ SDS for $10 \mathrm{~min}$ at $42^{\circ} \mathrm{C}$ and $0.5 \mathrm{X}$ SSC-0.1\% SDS for $30 \mathrm{~min}$ at $42^{\circ} \mathrm{C}$. Digoxigenin-labeled specific hybridization was visualized using an immunological detection system (Boehringer-Mannheim) employing anti-digoxigenin antibodies conjugated with alkaline phosphatase. Detection was performed using the chemiluminescent substrate disodium 3(4-methxyspiro; 1,2-dioxetane-3,2-(5-chloro)tricyclo(3.3.1., decan;-4-yl) phenylphosphate CSPD (Boehringer), according to the manufacturer's instructions. All blots were exposed to $\mathrm{X}$-ray film with intensifying screens at RT for $3 \mathrm{~h}$.
Dosage of OT in the cell supernatants. The production of OT by epithelial and myoepithelial cells derived from normal breast, as well as by breast carcinoma cell lines was assessed by means of an enzyme immunoassay (Oxytocin Enzyme Immunoassay kit, Assay Designs, Ann Arbor, MI). The presence of OT in the cell supernatants and in standard culture medium was tested following the kit instructions and peptide concentrations were determined by comparison to the provided standard. OT concentrations were determined both under basal culture conditions as well as following 12 or $48 \mathrm{~h}$ of treatment with $10 \mathrm{nM} \mathrm{E}_{2}$.

Modulation of OTR expression following $E_{2}$ treatment in breast carcinoma cell lines. Surface expression and modulation of OTR was investigated by flow cytometry analysis (FACSort, Becton-Dickinson, Milan, Italy), after treatment with $\mathrm{E}_{2} 10 \mathrm{nM}$ for $30 \mathrm{~min}$ in two ER-positive breast carcinoma cell lines (MCF7 and T47D). For OTR detection, $1 \times 10^{6}$ cells were incubated with $1 \mu \mathrm{g}$ of the anti-OTR IF3 mAb (6) for $1 \mathrm{~h}$ at $4{ }^{\circ} \mathrm{C}$, and then with the secondary antibody goat anti-mouse IgM-FITC conjugated (1:40 in PBS) (Sigma-Aldrich) for $45 \mathrm{~min}$ at $4^{\circ} \mathrm{C}$. The intensity of fluorescence was recorded on a logarithmic scale, by scoring at least 20,000 cells/sample; background fluorescence intensity was obtained by incubating the cells with the goat anti-mouse immunoglobulin reagent alone.

\section{Results}

OTR and OT mRNA in cell lines, and cell components from neoplastic and normal breast tissue. The presence of OTR and OT mRNA was studied in ten breast carcinoma cell lines, either ER-negative or positive by means of RT-PCR. The results are summarized in Table II. All the cell lines expressed OTR mRNA, whereas only 5/10 expressed OT mRNA. The hormone dependency (ER+ cells) of the tumor cell line was irrelevant with respect to OT mRNA expression.

Similarly, the presence of OTR and OT mRNA was tested in different cell subtypes isolated from specimens of normal tissues obtained from mastoplasties (both myoepithelial and epithelial component). RT-PCR was performed either in purified cell types, following separation, or in established primary cultures of both myoepithelial and epithelial cells. The results are summarized in Table III.

Table III. OT and OTR mRNA detection in selected component from human normal breast tissue.

\begin{tabular}{|c|c|c|c|c|}
\hline Case & Cell type & Separation & OT mRNA & OTR mRNA \\
\hline Freshly separated cells & Myoepithelial cells & Digestion+DB (CD10) & + & + \\
\hline Freshly separated cells & Epithelial cells & Digestion+DB (EMA) & + & + \\
\hline Established primary culture & Myoepithelial cells & & + & + \\
\hline Established primary culture & Epithelial cells & & + & + \\
\hline
\end{tabular}

DB, Dynabeads. 


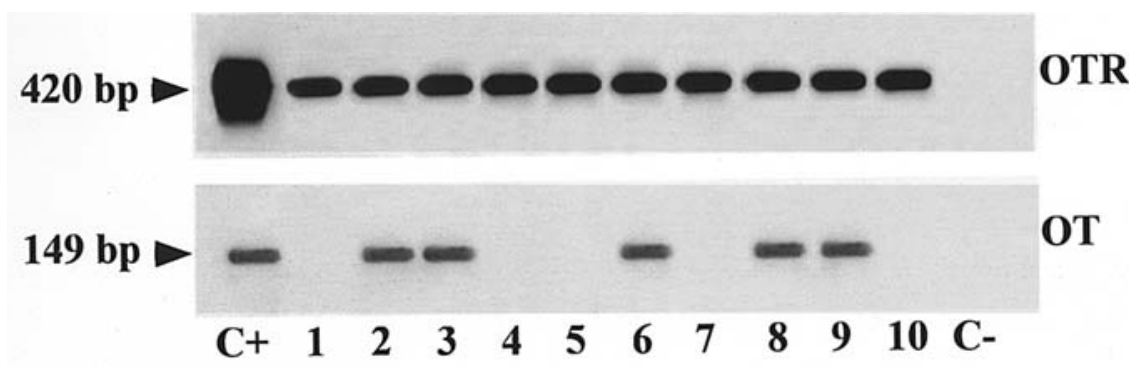

Figure 1. OT and OTR mRNA expression in breast carcinoma cell lines. Southern blot analysis of RT-PCR products of oxytocin receptor (OTR) and its ligand oxytocin (OT) in 10 human breast carcinoma cell lines (lane 1, MCF7; lane 2, T47D; lane 3, BT474; lane 4, ZR75; lane 5, Hs578t; lane 6, SKBR3; lane 7, MDA-MB4353; lane 8, BT549; lane 9, BT20; lane 10, MDA-MB-231; C-, negative control including omission of cDNA in the PCR mixture; $\mathrm{C}^{+}$, positive control corresponding to normal human hypothalamus for OT and BeWo choriocarcinoma cells for OTR). The corresponding base pair sizes were $420 \mathrm{bp}$ and $149 \mathrm{bp}$, respectively (arrow heads).

Table IV. OT levels $(\mathrm{pg} / \mathrm{ml})$ in the cells line supernatants.

\begin{tabular}{|c|c|c|c|c|c|}
\hline \multirow[b]{2}{*}{ Cell line } & \multirow[b]{2}{*}{$\begin{array}{c}\text { Medium } \\
(\mathrm{pg} / \mathrm{ml})\end{array}$} & \multicolumn{2}{|c|}{$\mathrm{OT}$ at $12 \mathrm{~h}$} & \multicolumn{2}{|c|}{ OT at $48 \mathrm{~h}$} \\
\hline & & $\begin{array}{c}\text { Basal } \\
(\mathrm{pg} / \mathrm{ml})\end{array}$ & $\begin{array}{c}\mathrm{E}_{2} \\
(\mathrm{pg} / \mathrm{ml})\end{array}$ & $\begin{array}{c}\text { Basal } \\
(\mathrm{pg} / \mathrm{ml})\end{array}$ & $\begin{array}{c}E_{2} \\
(\mathrm{pg} / \mathrm{ml})\end{array}$ \\
\hline BT474 & $3 \pm 1$ & $10 \pm 2$ & $38 \pm 5$ & $12 \pm 2$ & $53 \pm 3$ \\
\hline T47D & $3 \pm 2$ & $12 \pm 1$ & $96 \pm 4$ & $15 \pm 3$ & $129 \pm 5$ \\
\hline BT20 & $2 \pm 1$ & $7 \pm 1$ & $6 \pm 1$ & $10 \pm 1$ & $10 \pm 1$ \\
\hline Myoepithelial cells & $3 \pm 1$ & $18 \pm 3$ & $20 \pm 5$ & $24 \pm 5$ & $28 \pm 4$ \\
\hline Normal epithelial cells & $3 \pm 1$ & $3 \pm 2$ & $4 \pm 2$ & $4 \pm 1$ & $4 \pm 1$ \\
\hline
\end{tabular}

Data are mean \pm SD of three different experiments with cells seeded in quadruplicate. Basal levels versus medium in BT474, T47D and BT20 cells at 12 and 48 h: p<0.05. Basal levels versus $\mathrm{E}_{2}$-treated in BT474, and T47D cells at 12 and 48 h: p<0.001. Statistical analysis carried out by ANOVA.

Fig. 1 shows the presence of OTR and OT mRNA following Southern blot analysis in the cell lines tested.

OT levels detected in the cell culture media. By means of an immune-enzymatic assay OT concentration were dosed in the cultured medium of three breast carcinoma cell lines which were previously shown to contain OT mRNA by RT-PCR (T47D, BT474, BT20). OT release in the culture medium was evaluated in the epithelial and myoepithelial cells purified from normal breast tissue. Table IV summarized the results obtained, comparing the OT levels in the cell medium before culture, in the medium following 12 and $48 \mathrm{~h}$ of culture, in the medium following 12 and $48 \mathrm{~h}$ of cell culture in presence of $E_{2} 10 \mathrm{nM}$. In the breast cancer cells studied, the levels of OT in media collected after $48 \mathrm{~h}$ of culture ranged from 10 to $15 \mathrm{pg} / \mathrm{ml}$, compared to 2 to $3 \mathrm{pg} / \mathrm{ml}$ concentration in the mediums alone $(\mathrm{p}<0.05$, by ANOVA). In the two ERpositive cell lines, $\mathrm{E}_{2}$ determined a significant increase in OT concentrations (up to a 4.4-fold increase in BT474 and a 8.6 increase in T47D cells at $48 \mathrm{~h})(<0.001$, treated versus control, by ANOVA), and had no effect, as expected, in the ERnegative BT20 cell line. In myoepithelial cells, which displayed a significant basal OT-secretion ( $24 \mathrm{pg} / \mathrm{ml}$ at $48 \mathrm{~h}$ of culture) non-significant change in OT concentration occurred following
$\mathrm{E}_{2}$ treatment. Finally, normal epithelial cells did not secrete OT. Data reported in Table IV are mean \pm SD of three different experiments with cells seeded in quadruplicate.

OTR expression following $E_{2}$ treatment in breast carcinoma cell lines. The surface expression of OTR following $\mathrm{E}_{2}$ treatment was investigated by flow cytometry in MCF7 and T47D cells. In both cell lines, $30 \mathrm{~min}$ of $10 \mathrm{nM} \mathrm{E}_{2}$ treatment determined a 100 -fold increase in the OTR expression. Fig. 2 shows the pattern of OTR expression in T47D following $30 \mathrm{~min}$ incubation with $\mathrm{E}_{2} 10 \mathrm{nM}$.

\section{Discussion}

In the present study we provide the first demonstration of a local OT synthesis within the human mammary gland, under both normal and neoplastic conditions. Specifically, normal myoepithelial cells synthesize and secrete OT; different carcinoma cell lines are able to synthesize and release OT; and $E_{2}$ is a modulating factor in ER-positive cells involved in the regulation of such secretion.

The 'traditional' known sites of OT production mainly involve, among others (20), specific hypothalamic regions (21), ovary (22), heart (23), vasculature (24) and lympho- 

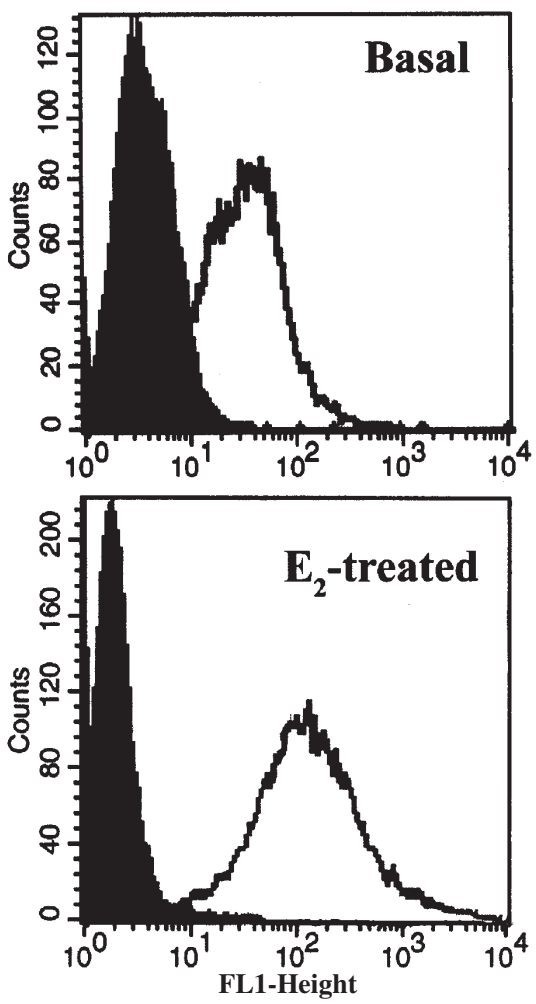

Figure 2. OTR modulation by $\mathrm{E}_{2}$ in T47D cells. By flow cytometry OTR expression in T47D breast cancer cells was significantly increased following $\mathrm{E}_{2}$ treatment. Dark profiles, unrelated $\mathrm{Ab}$. Each experiment was repeated at least twice with reproducible results. The levels shown refer to one single representative experiment

cytes (25). Besides these normal tissues, recently OT synthesis has been reported in lung small cell carcinoma cell lines as well (14).

In the mammary gland, the role of OT is mainly related to lactation $(26,27)$ under physiological conditions and to regulation of cancer cell growth under neoplastic conditions (8-10). In both situations myoepithelial or neoplastic epithelial cells respectively have been reported to express on their membrane surface functional OTR (6) which can bind OT derived from circulating blood. The effect of the OT/OTR binding results in a calcium-mediated contraction, for myoepithelial cells (28), and regulation of cancer cell proliferation, for breast carcinoma cells (8).

In the present study we provide the first evidence of a local synthesis of OT within the mammary gland. Although both normal epithelial and myoepithelial cells isolated from human breast contain the mRNA for OT, only myoepithelial cells actively produce and release OT in the culture medium. Such result suggests the possible existence of an unexpected local autocrine loop involving myoepithelial cells, which are known to be OTR positive, as reconfirmed in this study in the purified cell cultures. The role of OT in myoepithelial cells could be related to differentiation processes: in a previous study from our group, OT induced myoepithelial cell proliferation and differentiation in organotypic cultures of mouse mammary gland obtained from primed animals (29). Therefore, the existence of an intra-mammary synthesis of OT could represent a local peptide source directly available for myoepithelial cell differentiating processes.
In the normal mammary epithelial cells, both freshly isolated cells and established cultures, despite the presence of OT mRNA, no active OT synthesis and release in the culture medium was observed. When we moved from normal mammary epithelial cells to ten established breast carcinoma cell lines, we could observe that OT mRNA was present in $50 \%$ of the cell lines tested, irrespective to their hormonal dependency (ER-positive cells) or independency (ERnegative cells). The presence of the OT gene and the peptide synthesis in these breast carcinoma cell lines could be consistent with the subset of breast cancers reported to show a 'basal' phenotype, and to express markers of myoepithelial differentiation (18).

The OT mRNA present in these 5 out of 10 breast carcinoma cell lines is used to actively synthesize and release OT in the culture medium. The OT concentrations ranged from 7 to $15 \mathrm{pg} / \mathrm{ml}$ under basal culture conditions. Interestingly, such production is significantly increased after $\mathrm{E}_{2}$ treatment in ER-positive cells (up to an 8-fold increase in TD47D cells, increasing the peptide concentration to 129 $\mathrm{pg} / \mathrm{ml}$ ). The effect of $E_{2}$ on these cancer cells is on both the peptide synthesis and the receptor expression. By flow cytometry we could demonstrate that $E_{2}$ treatment significantly increased the quantity of OT binding sites on the cell surface of ER-dependent MCF7 and T47D breast carcinoma cell lines. This observation is consistent with the one previously reported by Amico and co-workers (13). The data obtained in the present study seem to support the idea of a relevant interplay between $\mathrm{E}_{2}$ and the OT/OTR system within the mammary gland, which can be enhanced by the evidence of a local intra-tumoral OT source. The $\mathrm{E}_{2}-\mathrm{OT}$ interplay probably follows a two-ways roundabout: not only $\mathrm{E}_{2}$ interferes with OTR expression and OT synthesis as here reported, but also OT may modulate ER $\alpha$ expression in breast cancer cells as demonstrated in a previous study from our group (12). However, ER-negative breast carcinoma cells also may synthesize OT, indicating that the role of the peptide is not exclusively limited to a selected 'steroidimprinted' cell population.

In different cell types, OT is known to play a double effect on cell proliferation, either inhibitory or stimulating; i.e., OT inhibits growth of breast carcinoma cells but enhances proliferation of endothelial cells $(3,10,25)$. Therefore, this local unexpected OT source within the breast carcinomas opens complex perspectives into additional mechanisms regulating tumor growth and possibly angiogenesis. The levels of OT here dosed in the culture medium (both under basal condition and following $\mathrm{E}_{2}$ stimulation) are at least 100 -fold lower than required $(100 \mathrm{nM})$ to determine an effect on breast carcinoma cell proliferation. In contrast, recently we demonstrated (unpublished data) that low OT concentration ( $1 \mathrm{nM})$ could determine migration and proliferation of tumor-associated endothelial cells derived from breast carcinomas. Altogether, these data suggest that by inducing OT synthesis in breast carcinoma cells, $\mathrm{E}_{2}$ could modulate vascular changes within the neoplastic tissue through a local paracrine loop. Further studies would be necessary to verify this challenging preliminary hypothesis.

In conclusion, in this study we provide the first evidence of a local synthesis of OT within the normal and neoplastic 
breast, which suggests that this peptide could play an autocrine/ paracrine role in this context, exerting different, various and possibly still unidentified biological effects.

\section{Acknowledgments}

This work was supported by grants from the M.U.R.S.T. (Rome), the A.I.R.C. (Milan) and the Compagnia di San Paolo 'Special Project Oncology' (Turin). A special thank you to Professor S.R. Lakhani and his co-workers at the Department of Histopathology, Royal Free and University College Medical School, University College, London, UK for kindly providing us with breast myoepithelial and epithelial cells.

\section{References}

1. Russel JA and Leng G: Sex, parturition and motherhood without oxytocin? J Endocrinol 57: 343-359, 1998.

2. Elands J, De Kloet ER and Wied D: Neurohypophyseal hormone receptors: relation to behavior. Prog Brain Res 91: 459-464, 1992.

3. Thibonnier M, Conarty DM, Preston JA, Plesnicher CL, Dweik RA and Erzurum SC: Human vascular endothelial cells express oxytocin receptors. Endocrinology 140: 1301-1309, 1999.

4. Bussolati G and Cassoni P: Editorial: the oxytocin/oxytocin receptor system-expect the unexpected. Endocrinology 142: 1377-1379, 2001.

5. Kimura T, Tanizawa O, Mori K, Brownstein MJ and Okayama H: Structure and expression of a human oxytocin receptor. Nature 356: 526-529, 1992.

6. Bussolati G, Cassoni P, Ghisolfi GP, Negro F and Sapino A: Immunolocalization and gene expression of oxytocin receptors in carcinomas and non-neoplastic tissues of the breast. Am J Pathol 148: 1895-1903, 1996.

7. Ito Y, Kobayashi T, Kimura T, et al: Investigation of the oxytocin receptor expression in human breast cancer tissue using newly established monoclonal antibodies. Endocrinology 137: 773-779, 1996.

8. Cassoni P, Sapino A, Negro F and Bussolati G: Oxytocin inhibits proliferation of human breast cancer cell lines. Virchows Arch 425: 467-472, 1994.

9. Cassoni P, Sapino A, Papotti M and Bussolati G: Oxytocin and oxytocin-analogue F314 inhibit cell proliferation and tumor growth of rat and mouse mammary carcinomas. Int J Cancer 66: 817-820, 1996.

10. Sapino A, Cassoni P, Stella A and Bussolati G: Oxytocin receptor within the breast: biological function and distribution. Anticancer Res 18: 2181-2186, 1998.

11. Cassoni P, Sapino A, Fortunati N, Munaron L, Chini B and Bussolati G: Oxytocin inhibits the proliferation of MDA-MB231 human breast-cancer cells via cyclic adenosine monophosphate and protein kinase A. Int J Cancer 72: 340-344, 1997.

12. Cassoni P, Catalano MG, Sapino A, Marrocco T, Fazzari A, Bussolati $\mathrm{G}$ and Fortunati N: Oxytocin modulates estrogen receptor alpha expression and function in MCF7 human breast cancer cells. Int J Oncol 21: 375-378, 2002.
13. Amico JA, Rauk PN and Cai HM: Estradiol and progesterone regulate oxytocin receptor binding and expression in human breast cancer cell lines. Endocrine 18: 79-84, 2002.

14. Pequeux C, Breton C, Hendrick JC, et al: Oxytocin syntesis and oxytocin receptor expression by cell lines of human small carcinoma of the lung stimulate tumor growth throwth autocrine/ paracrine signaling. Cancer Res 62: 4623-4629, 2002.

15. Cassoni P, Marrocco T, Sapino A, Allia E and Bussolati G: Evidence of oxytocin/oxytocin receptor interplay in human prostate gland and carcinomas. Int J Oncol 25: 899-904, 2004.

16. Stampfer M, Hallowes RC and Hackett AJ: Growth of normal human mammary cells in culture. In Vitro 16: 415-425, 1980.

17. Stampfer MR and Bartley JC: Human mammary epithelial cells in culture: differentiation and transformation. Cancer Treat Res 40: 1-24, 1988.

18. Jones C, Mackay A, Grigoriadis A, et al: Expression profiling of purified normal human luminal and myoepithelial breast cells: identification of novel prognostic markers for breast cancer. Cancer Res 64: 3037-3045, 2004.

19. Takemura T, Kimura S, Nomura S, et al: Expression and localization of human oxytocin receptor mRNA and its protein in chorion and decidua during parturition. J Clin Invest 93: 2319-2323, 1994

20. Gimpl G and Fahrenholz F: The oxytocin receptor system: structure, function, and regulation. Physiol Rev 81: 629-683, 2001.

21. Leng G, Brown CH and Russell JA: Physiological pathways regulating the activity of magnocellular neurosecretory cells. Prog Neurobiol 57: 625-655, 1999.

22. Stormshak F: Biochemical and endocrine aspects of oxytocin production by the mammalian corpus luteum. Reprod Biol Endocrinol 10: 92, 2003.

23. Jankowski M, Danalache B, Wang D, et al: Oxytocin in cardiac ontogeny. Proc Natl Acad Sci USA 101: 13074-13079, 2004.

24. Jankowski M, Wang D, Hajjar F, Mukaddam-Daher S, McCann SM and Gutkowska J: Oxytocin and its receptors are synthesized in the rat vasculature. Proc Natl Acad Sci USA 97: 6207-6211, 2000.

25. Cassoni P, Sapino A, Deaglio S, et al: Oxytocin is a growth factor for Kaposi's sarcoma cells: evidence of endocrine-immunological cross-talk. Cancer Res 62: 2406-2413, 2002.

26. Nishimori K, Young LJ, Guo Q, Wang Z, Insel TR and Matzuk MM: Oxytocin is required for nursing but is not essential for parturition or reproductive behavior. Proc Natl Acad Sci USA 93: 11699-11704, 1996.

27. Olins GM and Bremel RD: Oxytocin-stimulated myosin phosphorylation in mammary myoepithelial cells: roles of calcium ions and cyclic nucleotides. Endocrinology 114: 1617-1626, 1984.

28. Moore DM, Vogl AW, Baimbridge K and Emerman JT: Effect of calcium on oxytocin-induced contraction of mammary gland myoepithelium as visualized by NBD-phallacidin. J Cell Sci 88: 563-569, 1987.

29. Sapino A, Macri L, Tonda L and Bussolati G: Oxytocin enhances myoepithelial cell differentiation and proliferation in the mouse mammary gland. Endocrinology 133: 838-842, 1993. 